\title{
Utjecaj prešanja koštice buče i dodatka antioksidanasa na iskorištenje i oksidacijsku stabilnost hladno prešanog ulja
}

\begin{abstract}
Sažetak
Bučino ulje pripada grupi ekskluzivnih i vrlo skupih ulja gdje nutritivna kvaliteta opravdava visoku cijenu. $U$ ovom radu istraživan je utjecaj parametara hladnog prešanja bučinih koštica na iskorištenje ulja. Ispitivani su parametri frekvencija elektromotora, veličina otvora glave preše te dodatak ljuske suncokreta i mikrovalno zagrijavanje bučine koštice na proizvodnju ulja. Porastom frekvencije elektromotora i veličine otvora glave preše za izlaz pogače dolazi do smanjenja količine proizvedenog ulja. Primjenom standardnih metoda određeni su osnovni parametri kvalitete ulja: peroksidni broj, slobodne masne kiseline, udio netopljivih nečistoća i udio vlage. Također, ispitivan je dodatak mješavine prirodnih antioksidanasa na oksidacijsku stabilnost hladno prešanog bučinog ulja. Od antioksidanasa korišteni su ekstrakt nara, ekstrakt ružmarina (tip Oxy'Less Clear), eterično ulje primorskog vriska i eterično ulje bosiljka u kombinaciji sa ekstraktom zelenog čaja. Određivanje oksidacijske stabilnosti bučinog ulja provedeno je testom ubrzane oksidacije Schaal Oven testom $\left(63^{\circ} \mathrm{C}\right)$, a rezultat oksidacije ulja izražen je peroksidnim brojem. Rezultati istraživanja pokazuju da veličina otvora za izlaz pogače i frekvencija elektromotora utječu na iskorištenje hladno prešanog bučinog ulja. Najbolje antioksidacijsko djelovanje kod hladno prešanog bučinog ulja pokazao je dodatak mješavine ekstrakta zelenog čaja sa eteričnim uljem primorskog vriska.

Ključne riječi: bučino ulje, pužna preša, oksidacijska stabilnost, prirodni antioksidansi
\end{abstract}

\section{Uvod}

Proizvodnja hladno prešanog ulja ostvaruje se primjenom kontinuirane pužne preše pri čemu nema kondicioniranja sirovine niti primjene organskog otapala. Preradom uljarica postupkom hladnog prešanja osigurava se maksimalno zadržavanje aktivnih spojeva u ulju kao što su esencijalne masne kiseline, fenolne i flavonoidne tvari, tokoferoli, tokotrienoli, fitosteroli i dr. (Teh i Birch, 2013.) te zadržavanje karakterističnih senzorskih svojstva ulja. Ovim postupkom prešanja dobiva se sirovo ulje iz kojeg se moraju ukloniti sitne krute čestice i to sedimentacijom, filtracijom ili centrifugiranjem radi dobivanja finalnog proizvoda hladno prešanog ulja. Kao nusprodukt prešanja uljarica dobiva se pogača u kojoj zaostane određena količina ulja, značajni proteini, minerali, vlakna i drugi sastojci (Zubr, 1997.; Quezada i Cherian, 2012.). Jokić i sur. (2014.) istražuju optimizaciju proizvodnje hladno prešanog orahovog ulja primjenom pužne preše te utvrđuju da procesni parametri prešanja utječu na iskorištenje ulja. Moslavac i sur. (2014.) utvrđuju da procesni parametri hladnog prešanja utječu na iskorištenje ulja podlanka (Camelina sativa L.). Danas se hladno prešano bučino ulje (Oleum cucurbitae L.) proizvodi mehaničkim putem, prešanjem industrijske sorte buče (golica) na kontinuiranim pužnim prešama, a konzumira se kao salatno ulje (Fruhwirth, 2008.). Hladno prešano bučino ulje pripada grupi jestivih nerafiniranih ulja visoke nutritivne vrijednosti zbog povoljnog sastava masnih kiselina i drugih sastojaka koji pokazuju pozitivan učinak u organizmu tako što djeluju antimikrobno, diuretski, blokiraju slobodne radikale (Murković i Pfannhauser, 2000;; Neđeral, 2006.). Tokoferoli i tokotrienoli su prirodna skupina spojeva u biljnim uljima koji imaju antioksidacijska svojstva te štite ulje od oksidacijskog kvarenja. U bučinom ulju prevladava gama oblik toko-

Prof. dr. sc. Tihomir Moslavac, izv. prof. dr. sc. Stela Jokić, prof. dr. sc. Drago Šubarić, Tena Jurić,

Sveučlište Josipa Jurja Strossmayera, Prehrambeno-tehnološki fakultet Osijek, Franje Kuhača 20, 31000 0sijek, Hrvatska, Tihomir.Moslavac@ptfos.hr Hrvoje Krajna, Anastazija Konjarević, Hrvatski Veterinarski Institut, Veterinarski zavod Vinkovci, Josipa Kozarca 24, 32100 Vinkovci, Hrvatska Benjamin Muhamedbegović, Univerzitet u Tuzli, Tehnološki fakultet Tuzla, Univerzitetska 8, 75000 Tuzla, BiH 
ferola u količini oko $90 \%$ što doprinosi dobroj oksidacijskoj stabilnosti ulja (Vukša, 2003; Dimić, 2005.). Jestiva biljna ulja vrlo brzo podliježu nepoželjnim promjenama (kemijske reakcije, enzimski i mikrobiološki procesi) što rezultira kvarenjem ulja. Najčešća vrsta kvarenja ulja je autooksidacija koja može nastupiti brže ili sporije što ovisi od procesa proizvodnje, sastava ulja, uvjeta skladištenja, prisutnosti sastojaka koji ubrzavaju (prooksidansi) ili usporavaju (antioksidansi) ovu reakciju oksidacije (Martin-Polvillo, 2004.). Tijekom oksidacijskog kvarenja ulja dolazi do stvaranja primarnih i sekundarnih produkata oksidacije (Gray,1978; Rovellini, 1997.). Nastali produkti ovog kvarenja ulja u malim količinama daju neugodan miris čime narušavaju senzorska svojstva ulja (Broadbent i Pike, 2003.). Poznavanje stabilnosti (održivosti) biljnih ulja je važno kako bi se moglo unaprijed utvrditi vrijeme za koje se ulje može sačuvati od jače izražene oksidacije te za određivanje vremenskog roka upotrebe ulja. Brojna istraživanja oksidacijskog kvarenja biljnih ulja pokazuju da njihova održivost ovisi, prije svega, od vrste ulja odnosno sastava masnih kiselina te od vrste i udjela prirodnih antioksidanasa u ulju. Frega i sur. (1999.) u utvrđuju da slobodne masne kiseline u biljnom ulju djeluju kao prooksidansi, ubrzavaju oksidacijsko kvarenje ulja te kod većeg udjela smanjuju stabilnost ulja. Matthaus (1996.) ukazuje da udio pojedinih sastojaka utječe na stabilnost suncokretovog ulja, repičinog ulja i orahovog ulja. Danas se u praksi primjenjuju metode za određivanje oksidacijske stabilnosti biljnih ulja temeljene na ubrzanoj oksidaciji ulja: Oven test, AOM test i Rancimat test (Shahidi, 2005.; Suja, 2004.; Abramović, 2006.; Farhoosh, 2008.). Stabilnost biljnih ulja može se poboljšati dodatkom antioksidansa, a to su tvari koje usporavaju proces autooksidacije. Poznati su sintetski i prirodni antioksidansi koji se koriste za stabilizaciju biljnih ulja radi povećanja otpornosti prema oksidaciji (Yanishlieva i Marinova, 2001.; Merrill, 2008.). Danas se istražuju različiti biljni materijali naročito začinske biljke koji sadrže aktivne sastojke kao što su fenolni spojevi te pokazuju značajno antioksidacijsko djelovanje u biljnim uljima (Berra, 2006.; Bandoniene, 2000.). Tako je stabilizacija hladno prešanih ulja usmjerena na primjenu raznih ekstrakata začinskih biljaka (ružmarina, zelenog čaja, kadulje, origana, crnog bibera i dr.) u svrhu zaštite od oksidacijskog kvarenja (Pan, 2007.; Ahn, 2008.). Erkan i sur. (2008.) istražuju antioksidacijsku aktivnost ekstrakta ružmarina i drugih spojeva na stabilizaciju ulja. Gramza i sur. (2006.) izvještavaju da visoku antioksidacijsku aktivnost, mjerenu kao indukcijski period, pokazuje etanolni ekstrakt zelenog čaja u odnosu na aktivnost BHT i ekstrakta crnog čaja u suncokretovom ulju. Hraš i sur. (2000.) ukazuju na antioksidacijski i sinergistički efekt, posljedica ekstrakta ružmarina i alfa tokoferola kod stabilizacije suncokretovog ulja.

Cilj istraživanja ovog rada bio je ispitati utjecaj parametara hladnog prešanja bučinih koštica (frekvencija elektromotora, veličina otvora glave preše za izlaz pogače) te dodatka ljuske suncokreta i mikrovalnog zagrijavanja koštice na iskorištenje ulja. Na proizvedenom hladno prešanom bučinom ulju ispitivan je utjecaj dodatka mješavine prirodnih antioksidanasa ekstrakta ružmarina (tip Oxy'Less ${ }^{\circ}$ Clear), ekstrakta zelenog čaja, ekstrakta nara, eteričnog ulja bosiljka i eteričnog ulja primorskog vriska na oksidacijsku stabilnost ulja.

\section{Materijal i metode}

Ispitivanje utjecaja parametara prešanja na iskorištenje sirovog i hladno prešanog ulja provedeno je sa bučinom košticom (golica) sorte "Gleisdorf" koja je proizvedena u firmi Grbić d.o.o., Požega. Utjecaj dodatka antioksidanasa na oksidacijsku stabilnost proizvedenog hladno prešanog bučinog ulja proveden je sa prirodnim antioksidansima ekstraktom ružmarina (tip $\mathrm{Oxy}^{\prime}$ Less $^{\circ}$ Clear), ekstraktom zelenog čaja, ekstraktom nara, eteričnim uljem bosiljka i eteričnim uljem primorskog vriska (rtanjskog čaja). U istraživanju su korištene mješavine dva antioksidansa i to ekstrakta zelenog čaja u kombinaciji s pojedinim ispitivanim antioksidansom u udjelu $0,2 \%$. 
Oxy'Less $^{\circ}$ Clear je ekstrakt ružmarina u formulaciji viskozne tekućine, dobiven od listova ružmarina koje ima botaničko ime Romarinus officinalis L. Specifikacija ovog ekstrakta ružmarina: udjel karnosolne kiseline 4-5\%, zaštitni faktor (PF) je > 4,5, proizvođač Naturex, Francuska.

Ekstrakt zelenog čaja proizveden je iz lišća biljke Camellia sinensis L. Specifikacija ekstrakta zelenog čaja: udjel epigalokatehin galata (EGCG) je > 45\%, udjel ukupnih polifenola > 98\%, udjel kofeina $<0,5 \%$, udjel katehina $>80 \%$.

Ekstrakt nara proizveden je iz voćnog ploda nara (botaničko ime Punica granatum L.). Po sastavu je prirodni ekstrakt, maltododekstrin. Specifikacija ekstrakta nara 10: udjel elaginske kiseline je $>10 \%$, suhi ekstrakt $>95 \%$.

Eterično ulje bosiljka dobiveno je parnom destilacijom jednogodišnje, aromatične biljke bosiljak (Ocimum basilicum), odnosno njezinih cvjetnih vrhova. Proizvedeno je od strane Instituta za ratarstvo i povrtlarstvo, Novi Sad, Srbija.

Eterično ulje primorskog vriska je dobiveno također parnom destilacijom cvjetnih vrhova rtanjskog čaja (Satureja Montana). Proizvedeno je od strane Instituta za ratarstvo i povrtlarstvo, Novi Sad, Srbija.

\section{Određivanje udjela ulja u koštici i pogači}

Udio ulja u bučinoj koštici i pogači zaostaloj nakon prešanja određen je ekstrakcijom ulja po Soxhletu. Udio ulja se računa prema formuli:

a - masa tikvice s uljem (g);

$$
\text { Udio ulja \% }=(a-b) * 100 / c
$$

$\mathrm{b}$ - masa prazne tikvice $(\mathrm{g})$;

c - masa uzorka koji se ispituje (g).

Hladno prešanje

Količina ulja dobivena prešanjem (U) se računa prema formuli (Dimić, 2005.):

$\mathrm{U}$ - količina prešanog ulja (\%);

$$
U=U_{0}-U_{p}^{*}(a / b)(\%)
$$

$\mathrm{U}_{0}$ - udio ulja u sirovini (\%);

$\mathrm{U}_{\mathrm{p}}$ - udio ulja u pogači (\%);

a - suha tvar u sirovini (\%);

b - suha tvar u pogači (\%).

Stupanj djelovanja prešanja (P) računa se prema formuli:

$\mathrm{U}$ - količina prešanog ulja (\%);

$$
P=\left(U / U_{0}\right) * 100(\%)
$$

$\mathrm{U}_{0}$ - udio ulja u sirovini (\%).

Iz koštica buče, primjenom kontinuirane pužne preše postupkom hladnog prešanja, proizvedeno je sirovo ulje. Svaki uzorak imao je 1 kg koštica. Prilikom prešanja korišteni su procesni parametri: veličina otvora glave preše za izlaz pogače i frekvencija elektromotora kako bi se ispitao utjecaj na iskorištenje ulja. Sirovo bučino ulje taloženo je 14 dana u tamnom prostoru, a potom je provedena vakuum filtracija kako bi se što više uklonile netopljive nečistoće, zaostale iz bučine koštice te je dobiveno hladno prešano bučino ulje. 


\section{Određivanje osnovnih parametara kvalitete ulja}

Na proizvedenom hladno prešanom bučinom ulju određeni su osnovni parametri kvalitete (peroksidni broj, slobodne masne kiseline, udio vlage i netopljive nečistoće) te parametri za identifikaciju ulja jodni broj i saponifikacijski broj primjenom standardnih metoda.

\section{Slobodne masne kiseline}

Nastale slobodne masne kiseline (SMK) u ispitivanom hladno prešanom bučinom ulju određene su standardnom metodom (ISO 660: 1996) koja se temelji na principu titracije s otopinom natrij-hidroksida. Rezultat je prikazan kao udjel (\%) slobodnih masnih kiselina izražen kao oleinska kiselina prema jednadžbi:

SMK $(\%$ oleinske kiseline $)=\mathrm{V} \cdot \mathrm{c} \cdot \mathrm{M} / 10 \cdot \mathrm{m}$

$\mathrm{V}=$ utrošak otopine natrij-hidroksida za titraciju uzorka $(\mathrm{mL})$;

$\mathrm{c}=$ koncentracija otopine natrij-hidroksida za titraciju, $\mathrm{c}(\mathrm{NaOH})=0,1 \mathrm{~mol} / \mathrm{L}$;

$\mathrm{M}=$ molekulska masa oleinske kiseline, $\mathrm{M}=282 \mathrm{~g} / \mathrm{mol}$;

$\mathrm{m}=$ masa uzorka ulja za ispitivanje (g).

\section{Peroksidnibroj}

Peroksidni broj (Pbr) je pokazatelj stupnja oksidacijskog kvarenja biljnih ulja, a njegovo određivanje je jedna od najviše primjenjivanih metoda za ispitivanje primarnih produkata oksidacije ulja (hidroperoksidi, peroksidi). Peroksidni broj ispitivanog hladno prešanog bučinog ulja određen je standardnom metodom (ISO 3960:2007). Rezultat je izražen kao mmol aktivnog kisika koji potječe iz nastalih peroksida prisutnih u $1 \mathrm{~kg}$ ulja. Vrijednost se izračunava prema jednadžbi:

$$
\mathrm{Pbr}=\left(\mathrm{V}_{1}-\mathrm{V}_{0}\right) \cdot 5 / \mathrm{m} \quad\left(\mathrm{mmol} \mathrm{O}_{2} / \mathrm{kg}\right)
$$

$\mathrm{V}_{1}=$ volumen otopine natrij-tiosulfata, $\mathrm{c}\left(\mathrm{Na}_{2} \mathrm{~S}_{2} \mathrm{O}_{3}\right)=0,01 \mathrm{~mol} / \mathrm{L}$ utrošen za titraciju uzorka ulja (mL);

$\mathrm{V}_{0}=$ volumen otopine natrij-tiosulfata utrošen za titraciju slijepe probe $(\mathrm{mL})$;

$\mathrm{m}=$ masa uzorka ulja $(\mathrm{g})$.

\section{Udio vlage}

Količina vlage je određena u bučinoj koštici i u proizvedenom hladno prešanom ulju. Metoda korištena za određivanje je ISO 662:1992. Udio vlage izračunava se prema formuli:

$$
\text { Udio vode }=\frac{m 1-m 2}{m 1-m 0} \times 100
$$

$\mathrm{m}_{0}$ - masa staklene posudice $(\mathrm{g})$;

$\mathrm{m}_{1}$ - masa staklene posudice i uzorka prije sušenja (g);

$\mathrm{m}_{2}$ - masa staklene posudice i uzorka nakon sušenja $(\mathrm{g})$. 
Udio netopljivih nečistoća

Za određivanje netopljivih nečistoća korištena je standardna metoda ISO 663:1992.

Udio netopljivih nečistoća izračunava se prema formuli:

$$
\text { Udio netopljivih nečistoća }=\frac{m 2-m 1}{m 0} \times 100
$$

$\mathrm{m}_{0}$ - masa uzorka $(\mathrm{g})$;

$\mathrm{m}_{1}$ - masa osušenog lijevka;

$\mathrm{m}_{2}$ - masa lijevka s nečistoćama nakon sušenja $(\mathrm{g})$.

\section{Jodni broj}

Određivanjem jodnog broja ukazuje se na nezasićenost ulja ili masti. Jodni broj predstavlja količinu joda u gramima koja se veže na $100 \mathrm{~g}$ ulja ili masti.

Jodni broj se određuje prema formuli:

$$
\text { Jodni broj }=\frac{(V 0-V 1) \cdot 0,01269}{c} \quad(\mathrm{~g} / 100 \mathrm{~g})
$$

$\mathrm{V}_{0}=$ volumen utrošene $0,1 \mathrm{M}$ otopine natrij - tiosulfata za titraciju slijepe probe $(\mathrm{mL})$;

$\mathrm{V}_{1}=$ volumen utrošene $0,1 \mathrm{M}$ otopine natrij - tiosulfata za titraciju uzorka $(\mathrm{mL})$;

$\mathrm{c}=$ masa ispitivanog uzorka $(\mathrm{g})$.

\section{Saponifikacijski broj}

Saponifikacijski broj označava broj mg KOH koji je potreban za potpunu saponifikaciju slobodnih i esterski vezanih masnih kiselina u $1 \mathrm{~g}$ masti.

Saponifikacijski broj se određuje prema formuli:

Saponifikacijski broj $==\frac{(V 0-V 1) \cdot 2,81}{m} \quad(\mathrm{mg} \mathrm{KOH} / \mathrm{g} \mathrm{ulja})$

$\mathrm{V}_{0}=$ volumen $0,5 \mathrm{M}$ otopine $\mathrm{HCl}$ utrošen za titraciju slijepe probe $(\mathrm{mL})$;

$\mathrm{V}_{1}=$ volumen $0,5 \mathrm{M}$ otopine $\mathrm{HCl}$ utrošen za titraciju uzorka $(\mathrm{mL})$;

$\mathrm{m}=$ masa uzorka $(\mathrm{g})$.

$1 \mathrm{~mL} 0,5 \mathrm{M}$ otopine $\mathrm{HCl}$ ekvivalentan je $28,1 \mathrm{mg} \mathrm{KOH}$.

Određivanje oksidacijske stabilnosti ulja

Poznavanje oksidacijske stabilnosti (održivosti) jestivih biljnih ulja važno je kako bi se unaprijed odredilo vrijeme za koje se može sačuvati od jače izraženog oksidacijskog kvarenja, bez bitnih promjena kvalitete.

\section{Schaal Oven test}

Schaal Oven test (Oven test) je jedan od najstarijih testova za određivanje oksidacijske stabilnosti jestivih biljnih ulja. Primjenom ove metode uzorci hladno prešanog bučinog ulja sa i bez dodane mješavine dva prirodna antioksidansa se zagrijavaju u termostatu na konstantnoj temperaturi $63^{\circ} \mathrm{C}$ tijekom četiri dana. Tijekom testa kao rezultat ubrzane oksidacije ispitivanih uzoraka bučinog ulja praćena je promjena vrijednosti peroksidnog broja (svakih 24 sata). 


\section{Rezultati i rasprava}

Utjecaj parametara prešanja

Prije prešanja određen je udio ulja u košticama buče te je srednja vrijednost iznosila 46,48\%. Također je određen i udio vlage u košticama pri čemu je dobivena vrijednost $5,19 \%$. Rezultati ispitivanja utjecaja parametara prešanja bučine koštice na iskorištenje sirovog ulja i hladno prešanog ulja prikazani su u tablicama 1 i 2 . U tablici 1 vidljivi su rezultati utjecaja frekvencije elektromotora $(22,30,38 \mathrm{~Hz})$ koja regulira brzinu pužnice tijekom prešanja, na iskorištenje sirovog ulja i finalnog hladno prešanog bučinog ulja. Prešanjem bučine koštice (masa uzorka je $1 \mathrm{~kg}$ ) kod uvjeta frekvencije elektromotora $22 \mathrm{~Hz}(\mathrm{~F})$, veličine otvora za izlaz pogače (N) promjera $8 \mathrm{~mm}$ i temperature zagrijavanja glave preše $100^{\circ} \mathrm{C}$ (T) proizvedeno je $230 \mathrm{~mL}$ sirovog ulja temperature $45^{\circ} \mathrm{C}$. Sirovo ulje sadrži sitne krute čestice koje predstavljaju netopljive nečistoće iz same koštice, moraju se ukloniti iz ulja kako bi dobili finalni proizvod hladno prešano bučino ulje. Nakon 14 dana sedimentacije (prirodno taloženje) te vakuum filtracije sirovog ulja dobiveno je 109 mL hladno prešanog bučinog ulja. Analizom pogače (nusprodukt prešanja) utvrđeno je 34,64\% zaostalog ulja pri čemu je izračunat stupanj djelovanje preše $25,67 \%$. Porastom fre-

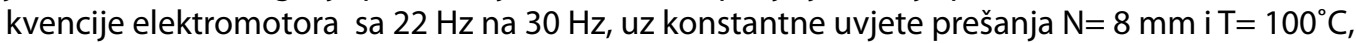
proizvedena je manja količina sirovog ulja (208 mL) temperature $39^{\circ} \mathrm{C}$, a nakon sedimentacije i filtracije imamo $98 \mathrm{~mL}$ hladno prešanog bučinog ulja. Određen je veći udio zaostalog ulja $u$ pogači 38,47\% te je ostvaren manji stupanj djelovanja preše (17,39\%). Primjenom još veće frekvencije elektromotora $(38 \mathrm{~Hz}$ ), povećava se brzina pužnice što rezultira još većim smanjenjem volumena proizvedenog sirovog ulja $(178 \mathrm{~mL})$ i finalnog ulja $(88 \mathrm{~mL})$ uz mali porast udjela zaostalog ulja u pogači (39,83\%). Temeljem dobivenih rezultata utjecaja frekvencije elektromotora na iskorištenje ulja može se zaključiti da se porastom frekvencije elektromotora, kod navedenih uvjeta prešanja bučine koštice, smanjuje volumen proizvedenog sirovog ulja i hladno prešanog ulja. Također, dolazi do porasta udjela zaostalog ulja u pogači što doprinosi manjem stupanju djelovanja preše. Objašnjenje ove pojave da se primjenom veće frekvencije elektromotora tijekom prešanja proizvede manja količina ulja iz bučine koštice može se tumačiti tako što se materijal u sustavu preše krače vrijeme zadržava, a to utječe na efikasnost cijeđenja ulja.

Tablica 1. Utjecaj frekvencije elektromotora (brzine pužnice) kod prešanja bučine koštice na iskorištenje bučinog ulja.

Table 1. Effect of frequency electricmotor (speed screw) during pressing pumpkin seeds on yield pumpkin oil.

\begin{tabular}{|c|c|c|c|c|c|c|c|c|}
\hline Uzorak & $\begin{array}{c}\text { Masa } \\
\text { sirovine } \\
(\mathbf{k g})\end{array}$ & $\begin{array}{c}\text { Volumen } \\
\text { sirovog } \\
\text { ulja } \\
\text { (mL) }\end{array}$ & $\begin{array}{l}\text { Temp. } \\
\text { sirovog } \\
\text { ulja } \\
\left({ }^{\circ} \mathrm{C}\right)\end{array}$ & $\begin{array}{c}\text { Vol.ulja } \\
\text { nakon } \\
14 \text { dana } \\
\text { taloženja } \\
\text { i vacum } \\
\text { filtriranja } \\
\text { (mL) }\end{array}$ & $\begin{array}{c}\text { Masa } \\
\text { dobivene } \\
\text { pogače } \\
\text { (g) }\end{array}$ & $\begin{array}{c}\text { Udio ulja } \\
\text { u pogači } \\
\text { (\%) }\end{array}$ & $\begin{array}{c}\text { Udio vode } \\
\text { u pogači } \\
\text { (\%) }\end{array}$ & $\begin{array}{c}\text { Stupanj } \\
\text { djelovanja } \\
\text { preše } \\
(\%)\end{array}$ \\
\hline $\begin{array}{l}\mathrm{N}=8 \mathrm{~mm} \\
T=100^{\circ} \mathrm{C} \\
\mathrm{F}=\mathbf{2 2} \mathbf{H z}\end{array}$ & 1 & 230 & 45 & 109 & 744,56 & 34,64 & 5,91 & 25,67 \\
\hline $\begin{array}{l}\mathrm{N}=8 \mathrm{~mm} \\
\mathrm{~T}=100{ }^{\circ} \mathrm{C} \\
\mathrm{F}=\mathbf{3 0} \mathbf{H z}\end{array}$ & 1 & 208 & 39 & 98 & 817,56 & 38,47 & 6,03 & 17,39 \\
\hline $\begin{array}{l}\mathrm{N}=8 \mathrm{~mm} \\
\mathrm{~T}=100{ }^{\circ} \mathrm{C} \\
\mathrm{F}=\mathbf{3 8} \mathbf{H z}\end{array}$ & 1 & 178 & 50 & 88 & 826,27 & 39,83 & 6,04 & 14,44 \\
\hline
\end{tabular}


Udio ulja u bučinoj koštici je 46,48\%, a udio vode 5,19\%.

$\mathrm{N}$ - veličina otvora glave preše, definira promjer pogače $(\mathrm{mm})$;

$\mathrm{F}$ - frekventni regulator, regulira brzinu pužnice preše $(\mathrm{Hz})$;

$\mathrm{T}$ - temperatura grijača glave preše kod izlaza pogače $\left({ }^{\circ} \mathrm{C}\right)$;

Rezultati ispitivanja utjecaja veličine otvora glave preše $(N)$ kod prešanja bučine koštice na iskorištenje sirovog ulja i hladno prešanog ulja prikazani su u tablici 2. Prešanjem bučine koštice kod uvjeta: nastavak koji definira veličinu otvora glave preše za izlaz pogače $\mathrm{N}=7 \mathrm{~mm}, \mathrm{~T}=$ $100{ }^{\circ} \mathrm{C}$ i $\mathrm{F}=22 \mathrm{~Hz}$ dobiveno je $352 \mathrm{~mL}$ sirovog ulja temperature $46^{\circ} \mathrm{C}$. Nakon 14 dana taloženja i vakuum filtracije proizvedeno je $146 \mathrm{~mL}$ hladno prešanog bučinog ulja. Analitički je utvrđen udio zaostalog ulja u pogači $34,18 \%$. Primjenom otvora za izlaz pogače većeg promjera $\mathrm{N}=8$ $\mathrm{mm}$ proizvedena je manja količina sirovog ulja $(230 \mathrm{~mL}$ ) i finalnog ulja (109 mL). Korištenjem nastavka za izlaz pogače promjera $\mathrm{N}=10 \mathrm{~mm}$, kod konstantne frekvencije elektromotora $\mathrm{F}=$ $22 \mathrm{~Hz}$ i temperature zagrijavanja glave preše $\mathrm{T}=100^{\circ} \mathrm{C}$ prešanjem bučine koštice, dobiven je volumen sirovog ulja $130 \mathrm{~mL}$ s temperaturom $40^{\circ} \mathrm{C}$ što zadovoljava Pravilnik o jestivim uljima i mastima NN 41/12. Nakon 14 dana sedimentacije i vakuum filtracije sirovog bučinog ulja, dobiven je finalni proizvod hladno prešano bučino ulje u količini od $48 \mathrm{~mL}$. Analizom količine zaostalog ulja u pogači, dobivena je vrijednost 37,74 \% što ukazuje na nizak stupanj djelovanja preše. Iz navedenih rezultata zaključujemo da veličina otvora glave preše utječe na iskorištenje ulja kod proizvodnje hladno prešanog bučinog ulja, uz konstantnu frekvenciju elektromotora $22 \mathrm{~Hz}$ i temperaturu glave preše $100^{\circ} \mathrm{C}$. Što je veličina otvora za izlaz pogače na glavi preše manja, to je radni tlak tijekom prešanja veći pa se proizvede veća količina sirovog ulja i hladno prešanog ulja te je manje zaostalog ulja u pogači (Rac, 1964.; Moslavac i sur., 2014.).

Tablica 2. Utjecaj veličine otvora glave preše kod prešanja bučine koštice na iskorištenje bučinog ulja.

Table 2. Effect of nozzle size head presses during pressing pumpkin seeds on yield pumpkin oil.

\begin{tabular}{|c|c|c|c|c|c|c|c|c|}
\hline Uzorak & $\begin{array}{c}\text { Masa } \\
\text { sirovine } \\
(\mathbf{k g})\end{array}$ & $\begin{array}{c}\text { Volumen } \\
\text { sirovog } \\
\text { ulja } \\
\text { (mL) }\end{array}$ & $\begin{array}{l}\text { Temp. } \\
\text { sirovog } \\
\text { ulja } \\
\left({ }^{\circ} \mathrm{C}\right)\end{array}$ & $\begin{array}{c}\text { Volumen } \\
\text { ulja nakon } \\
14 \text { dana } \\
\text { taloženja } \\
\text { i vacum } \\
\text { filtriranja } \\
\text { (mL) }\end{array}$ & $\begin{array}{c}\text { Masa } \\
\text { dobivene } \\
\text { pogače } \\
\text { (g) }\end{array}$ & $\begin{array}{c}\text { Udio ulja } \\
\text { u pogači } \\
\text { (\%) }\end{array}$ & $\begin{array}{c}\text { Udio vode } \\
\text { u pogači } \\
\text { (\%) }\end{array}$ & $\begin{array}{c}\text { Stupanj } \\
\text { djelovanja } \\
\text { preše } \\
(\%)\end{array}$ \\
\hline $\begin{array}{l}\mathrm{N}=\mathbf{7} \mathbf{~ m m} \\
\mathrm{T}=100^{\circ} \mathrm{C} \\
\mathrm{F}=22 \mathrm{~Hz}\end{array}$ & 1 & 352 & 46 & 146 & 730,51 & 34,18 & 6,04 & 26,46 \\
\hline $\begin{array}{l}\mathrm{N}=\mathbf{8} \mathbf{\mathbf { m m }} \\
\mathrm{T}=100^{\circ} \mathrm{C} \\
\mathrm{F}=22 \mathrm{~Hz}\end{array}$ & 1 & 230 & 45 & 109 & 744,56 & 34,64 & 5,91 & 25,67 \\
\hline $\begin{array}{l}\mathrm{N}=\mathbf{1 0} \\
\mathbf{m m} \\
\mathrm{T}=100{ }^{\circ} \mathrm{C} \\
\mathrm{F}=22 \mathrm{~Hz}\end{array}$ & 1 & 130 & 40 & 48 & 824,32 & 37,74 & 6,11 & 19,00 \\
\hline
\end{tabular}


U tablici 3. prikazani su rezultati ispitivanja utjecaja dodatka ljuske suncokreta (10\%) i mikrovalnog zagrijavanja bučine koštice prije prešanja ( 3 min kod snage uređaja $800 \mathrm{~W}$ ) na iskorištenje ulja. Ovdje je prešanje bučine koštice provedeno kod uvjeta $\mathrm{N}=8 \mathrm{~mm}, \mathrm{~T}=100^{\circ} \mathrm{C}$ i F $=22$ Hz. Dodatkom ljuske suncokreta u uzorak bučine koštice i prešanjem proizvedena je veća količina sirovog ulja ( $272 \mathrm{~mL}$ ) u odnosu na prešanje koštice bez dodatka ljuske suncokreta. Nakon 14 dana taloženja i vakuum filtracije sirovog ulja proizvedena je znatno veća količina hladno prešanog ulja (145 mL), dok je udio zaostalog ulja u pogači bio nešto manji, a veći stupanj djelovanja preše. Provedbom mikrovalnog zagrijavanja uzorka bučine koštice na $800 \mathrm{~W}$ tijekom 3 minute došlo je do porasta temperature uzorka $\left(69^{\circ} \mathrm{C}\right)$, pa je prešanjem dobivena manja količina sirovog ulja $(210 \mathrm{~mL})$, kao i hladno prešanog ulja $(104 \mathrm{~mL})$ od uzorka bez termičkog tretiranja. Iz ovoga zaključujemo da dodatak male količine suncokretove ljuske (10\%) povećava količinu sirovog i hladno prešanog ulja pa je sukladno time i ekonomski isplativo. Dok se mikrovalno zagrijavanje uzorka prije prešanja nije pokazalo efikasno za porast iskorištenja ulja.

Tablica 3. Utjecaj ljuske suncokreta i mikrovalnog zagrijavanja bučine koštice na iskorištenje ulja.

Table 3. Effect of sunflower shell and microwave heating of pumpkin seeds on yield oil.

\begin{tabular}{|c|c|c|c|c|c|c|c|c|}
\hline Uzorak & $\begin{array}{c}\text { Masa } \\
\text { sirovine } \\
(\mathbf{k g})\end{array}$ & $\begin{array}{c}\text { Volumen } \\
\text { sirovog } \\
\text { ulja } \\
\text { (mL) }\end{array}$ & $\begin{array}{l}\text { Temp. } \\
\text { sirovog } \\
\text { ulja } \\
\left({ }^{\circ} \mathrm{C}\right)\end{array}$ & $\begin{array}{c}\text { Volumen } \\
\text { ulja nakon } \\
14 \text { dana } \\
\text { taloženja } \\
\text { i vacum } \\
\text { filtriranja } \\
\text { (mL) }\end{array}$ & $\begin{array}{c}\text { Masa } \\
\text { dobivene } \\
\text { pogače } \\
\text { (g) }\end{array}$ & $\begin{array}{c}\text { Udio ulja } \\
\text { u pogači } \\
\text { (\%) }\end{array}$ & $\begin{array}{c}\text { Udio vode } \\
\text { u pogači } \\
\text { (\%) }\end{array}$ & $\begin{array}{c}\text { Stupanj } \\
\text { djelovanja } \\
\text { preše } \\
(\%)\end{array}$ \\
\hline $\begin{array}{l}\mathrm{N}=8 \mathrm{~mm} \\
\mathrm{~T}=100^{\circ} \mathrm{C} \\
\mathrm{F}=22 \mathrm{~Hz}\end{array}$ & 1 & 230 & 45 & 109 & 744,56 & 34,64 & 5,91 & 25,47 \\
\hline $\begin{array}{c}\mathrm{N}=8 \mathrm{~mm} \\
\mathrm{~T}=100^{\circ} \mathrm{C} \\
\mathrm{F}=\underset{\left({ }^{*}\right)}{22 \mathrm{~Hz}}\end{array}$ & 1 & 272 & 48 & 145 & 846,85 & 33,65 & 6,06 & 27,60 \\
\hline $\begin{array}{l}\mathrm{N}=8 \mathrm{~mm} \\
\mathrm{~T}=100^{\circ} \mathrm{C} \\
\mathrm{F}=\underset{\left({ }^{* *}\right)}{22 \mathrm{~Hz}}\end{array}$ & 1 & 210 & 48 & 104 & 723,84 & 34,95 & 5,87 & 24,81 \\
\hline
\end{tabular}

* - uzorku se dodalo $10 \%$ ljuske suncokreta

** - uzorak se zagrijao u mikrovalnoj pećnici 3 minute na $800 \mathrm{~W}$ pri čemu se dobila temperatura uzorka $69^{\circ} \mathrm{C}$

\section{Kvaliteta proizvedenog ulja}

Na svježe proizvedenom hladno prešanom bučinom ulju provedena je analiza kemijskih karakteristika tj. osnovnih parametara kvalitete (peroksidni broj, slobodne masne kiseline, vlaga i netopljive nečistoće) prema Pravilniku o jestivim uljima i mastima (NN 41/2012) te parametri za identifikaciju ulja (jodni broj i saponifikacijski broj). Rezultati ovih analiza (Tablica 4.) pokazuju da je ulje dobre kvalitete s obzirom da su vrijednosti ispitivanih parametara kvalitete ulja u skladu s Pravilnikom. 
Tablica 4. Kemijske karakteristike ispitivanog bučinog ulja

Table 4. Chemical characteristics of the tested pumpkin oil

\begin{tabular}{|c|c|}
\hline Parametar kvalitete & $\begin{array}{c}\text { Bučino ulje } \\
\text { (hladno prešano) }\end{array}$ \\
\hline $\begin{array}{c}\mathrm{Pbr} \\
\left(\mathrm{mmol} \mathrm{O}_{2} / \mathrm{kg}\right)\end{array}$ & 1,70 \\
\hline $\begin{array}{c}\text { SMK } \\
\text { (\% oleinske kiseline) }\end{array}$ & 0,66 \\
\hline Voda (\%) & 0,099 \\
\hline Netopljive nečistoće (\%) & 0,11 \\
\hline Jodni broj $\left(\mathrm{g} \mathrm{I}_{2} / 100 \mathrm{~g}\right)$ & 105,27 \\
\hline $\begin{array}{l}\text { Saponifikacijski broj } \\
(\mathrm{mg} \mathrm{KOH} / \mathrm{g})\end{array}$ & 189,43 \\
\hline
\end{tabular}

\section{Oksidacijska stabilnost ulja}

Test ubrzane oksidacije bučinog ulja, sa i bez dodatka mješavine antioksidanasa, proveden je primjenom Schaal Oven testa (Oven test) kod temperature $63^{\circ} \mathrm{C}$ tijekom 4 dana, praćenjem peroksidnog broja (Pbr) svakih 24 sata (Tablica 5). Hladno prešano bučino ulje ima početni peroksidni broj $1,70 \mathrm{mmol} \mathrm{O}_{2} / \mathrm{kg}$, a tijekom četiri dana testa postepeno se vrijednost povećavala do 4,39 $\mathrm{mmol} \mathrm{O}_{2} / \mathrm{kg}$. Ovako niska vrijednost Pbr nakon četiri dana testa ukazuje na dobru održivost, tj. otpornost ovog ulja prema oksidacijskom kvarenju što se pripisuje sastavu masnih kiselina (dominira oleinska kiselina) i visokom udjelu $\gamma$-tokoferola (90\%) koji ima odlično antioksidacijsko djelovanje. Ispitivanjem utjecaja dodatka mješavine prirodnih antioksidanasa eteričnog ulja primorskog vriska i ekstrakta zelenog čaja $(0,1 \%+0,1 \%)$, postignuta je najveća zaštita bučinog ulja od oksidacijskog kvarenja. Na kraju testa ulje je imalo nižu vrijednost Pbr $\left(2,99 \mathrm{mmol} \mathrm{O}_{2} / \mathrm{kg}\right)$. Mješavina eteričnog ulja bosiljka i ekstrakta zelenog čaja ima malo manju efikasnost zaštite bučinog ulja od oksidacije, nakon testa $\mathrm{Pbr}$ je $3,47 \mathrm{mmol} \mathrm{O}_{2} / \mathrm{kg}$. Primjenom mješavine ekstrakta ružmarina i ekstrakta zelenog čaja, kao i mješavine ekstrakta nara i zelenog čaja, također se zapaža zaštita bučinog ulja od oksidacijskog kvarenja. Na kraju testa vrijednost Pbr je bila veća u odnosu na primjenu prethodnih mješavina antioksidanasa. $U$ radu Pokorny i sur. (1997.) su pokazali da acetonski ekstrakt ružmarina i kadulje produljuje stabilnost suncokretovog ulja, odnosno povećava oksidacijsku stabilnost suncokretovog ulja. Frankel i sur. (1997.) su prikazali da se antioksidacijska aktivnost ekstrakta zelenog čaja ponaša različito u različitim lipidnim sistemima. Petrik (2009.) zapaža da je mehanizam djelovanja ekstrakta zelenog čaja učinkovit u zaustavljanju procesa oksidacije samo u slučaju male koncentracije hidroperoksida. 
Tablica 5. Oksidacijska stabilnost hladno prešanog bučinog ulja određena Schaal Oven testom tijekom 4 dana praćena peroksidnim brojem svakih $24 \mathrm{~h}$.

Table 5. Oxidative stability of cold-pressed pumpkin seed oil determined by the Schaal Oven test during 4 days follow of peroxide values each 24 hours.

\begin{tabular}{|c|c|c|c|c|c|c|}
\hline \multirow{2}{*}{ Uzorak } & \multirow{2}{*}{$\begin{array}{c}\text { Udio } \\
\text { antioksidansa (\%) }\end{array}$} & \multicolumn{5}{|c|}{$\mathrm{Pbr}(\mathrm{mmol} \mathrm{O} / \mathbf{k g})$} \\
\hline & & 0.dan & 1.dan & 2.dan & 3.dan & 4.dan \\
\hline $\begin{array}{c}\text { Bučino ulje } \\
\text { (hladno prešano) }\end{array}$ & 0 & 1,70 & 2,43 & 2,99 & 3,50 & 4,39 \\
\hline $\begin{array}{l}\text { Eterično ulje } \\
\text { bosiljka + ekstrakt } \\
\text { zelenog čaja }\end{array}$ & $0,1+0,1$ & 1,70 & 1,98 & 2,47 & 3,00 & 3,47 \\
\hline $\begin{array}{l}\text { Eterično ulje } \\
\text { primorskog } \\
\text { vriska + ekstrakt } \\
\text { zelenog čaja }\end{array}$ & $0,1+0,1$ & 1,70 & 1,74 & 1,74 & 1,95 & 2,99 \\
\hline $\begin{array}{c}\text { Ekstrakt } \\
\text { ružmarina }+ \\
\text { ekstrakt zelenog } \\
\text { čaja }\end{array}$ & $0,1+0,1$ & 1,70 & 2,25 & 2,99 & 3,19 & 3,72 \\
\hline $\begin{array}{c}\text { Ekstrakt nara + } \\
\text { ekstrakt zelenog } \\
\text { čaja }\end{array}$ & $0,1+0,1$ & 1,70 & 2,18 & 3,47 & 3,72 & 3,92 \\
\hline
\end{tabular}

\section{Zaključak}

Na temelju ispitivanja parametara prešanja bučine koštice na iskorištenje ulja te dodatka mješavine prirodnih antioksidanasa na oksidacijsku stabilnost hladno prešanog bučinog ulja, mogu se navesti sljedeći zaključci. Frekvencija elektromotora, koja određuje brzinu pužnice tijekom prešanja, utječe na proizvodnju sirovog ulja i hladno prešanog bučinog ulja. Primjenom manje vrijednosti frekvencije elektromotora $(22 \mathrm{~Hz})$ proizvedena je veća količina sirovog ulja i hladno prešanog ulja, a manje je ulja zaostalo u pogači u odnosu na primjenu 30 i $38 \mathrm{~Hz}$. Veličina otvora glave preše za izlaz pogače utječe na iskorištenje bučinog ulja tijekom hladnog prešanja. Prešanjem koštice kod veličine otvora glave preše promjera $7 \mathrm{~mm}$, pri konstantnoj brzini pužnice i temperature glave preše, dobivena je veća količina sirovog i hladno prešanog ulja. Primjenom nastavka za izlaz pogače promjera 8 i $10 \mathrm{~mm}$ smanjuje se količina proizvedenog hladno prešanog bučinog ulja uz porast udjela zaostalog ulja u pogači i smanjenje stupnja djelovanja preše. Dodatkom ljuske suncokreta (10\%) u bučinu košticu dolazi do znatnog porasta količine proizvedenog sirovog i hladno prešanog ulja. Termičkim tretiranjem bučine koštice prije prešanja u mikrovalnoj pećnici na $800 \mathrm{~W}$ kroz 3 min dobiva se manja količina hladno prešanog ulja te se postupak nije pokazao kao prihvatljiv. Dodatkom mješavine prirodnih antioksidanasa koju čini ekstrakt zelenog čaja u kombinaciji sa eteričnim uljem primorskog vriska u hladno prešano bučino ulje postiže se veća razina zaštite ulja od oksidacijskog kvarenja. Ekstrakt zelenog čaja sa eteričnim uljem bosiljka kao i kombinacija sa ekstraktom ružmarina te ekstraktom nara također štite bučino ulje od oksidacijskog kvarenja ali imaju manju efikasnost zaštite. 


\section{Literatura}

Abramović, H, Abram, H. (2006). Effect of added rosemary extract on oxidative stability of Camelina sativa oil. Acta agriculturae Slovenica, 87 (2), 255-261.

Ahn, J-H., Kim, Y-P., Seo, E-M., Choi, Y-K., Kim, H-S. (2008). Antioxidant effect of natural plant extracts on the microencapsulated high oleic sunflower oil. Journal of Food Engineering, 84, 327-334.

Bandoniene, D., Pukalskas, A., Venskutonis, P.R. and Gruzdiene (2000). Preliminary screening of antioxidant activity of some plant extracts in rapeseed oil. Food Res. Int., 33, 785-791.

Berra, D., Lahiri, D., Nag, A. (2006). Studies on a natural antioxidant for stabilization of edible oil and comparasion with synthetic antioxidant. J. Food Eng., 74, 542-545.

Broadbent, C.J., Pike, O.A. (2003). Oil stability indeks correlated with sensory determination of oxidative stability in canola oil. Journal of the American Oil Chemists Society, 80, 59-63.

Dimić, E. (2005). Hladno ceđena ulja. Tehnološki fakultet Novi Sad.

Erkan, N., Ayranci, G., Ayranci, E. (2008). Antioxidant activities of rosemary (Rosmarinus Officinalis L.) extract blackseed (Nigella sativa L.) essential oil, carnosic acid, rosmarinic acid and sesamol. Food Chem., 110, 76-82.

Farhoosh, R., Niazmand, R., Rezaei, M., Sarabi, M. (2008). Kinetic parameter determination of vegetable oil oxidation under Rancimat test conditions. European Journal of Lipid Science and Technology, 110 (6), 587-592.

Frega, N., Mozzon, M., Lercker, G. (1999). Effect of Free Fatty Acids on Oxidative Stability of Vegetable Oil. Journal of the American Oil Chemists Society, 76 (3), 325-329.

Fruhwirth, G.O., Hermetter, A. (2008). Production technology and characteristic of Styrian pumpkin seed oil. European Journal of Lipid Science and Technology, 110 (7), 637-644.

Gramza, A., Khokhar, S., Yoko, S., Gliszczynska-Swiglo, A., Hes, M., Korczak, J. (2006). Antioxidant activity of tea extracts in lipids and correlation with polyphenol content. European Journal of Lipid Science and Technology, 108, 351362.

Gray, J.I. (1978). Measurement of lipid oxidation: a review. Journal of the American Oil Chemists Society, 55, 539-546.

Hraš, A. R., Hadolin, M., Knez, Ž., Bauman, D. (2000). Comparasion of antioxidative and synergistic effects of rosemary extract with a - tocopherol, assorbyl palmitate and citric acid in sunflower oil. Food Chem., 71, 229-233.

Yanishlieva, Nedyalka V., Marinova, Emma M. (2001). Stabilisation of edible oils with natural antioxidants. European Journal of Lipid Science and Technology, 103, 752-767.

Martin-Polvillo, M., Marquez-Ruiz, G., Dobarganes, M.C. (2004). Oxidative stability of sunflower oils differing in unsaturation degree during long-term storage at room temperature. Journal of the American Oil Chemists Society, 81, 577-583.

Matthaus, B.W. (1996). Determination of the Oxidative Stability of Vegetable Oils by Rancimat and Conductivity and Chemiluminescence Measurements. Journal of the American Oil Chemists Society, 73 (8), 1039-1043.

Merrill, L.I., Pike, O.A., Ogden, L.V. (2008). Oxidative Stability of Conventional and High-Oleic Vegetable Oils with Added Antioxidants. Journal of the American Oil Chemists Society, 85, 771-776.

Moslavac, T., Jokić, S., Šubarić, D., Aladić, K., Vukoja, J., Prce, N. (2014). Pressing and Supercritical CO, extraction of Camellina sativa oil. Ind. Cro. Prod., 54, 122-129.

Murković, M., Pfannhauser, W. (2000). Stability of pumpkin seed oil. European Journal of Lipid Science and Technology, 102 (10), 607-611.

Neđeral, N.S., Rade, D., Škevin, D., Štrucelj, D., Mokrovčak, Ž., Bartolić, M. (2006). Chemical characteristic of oils from naked and husk seeds of Cucrbita pepo L. Eur. J. Lipid Sci. Tech., 108, 936 - 943.

Quezada, N., Cherian, G. (2012). Lipid characterization and antioxidant status of the seeds and meals of Camelina sativaand flax. Eur. J. Lipid Sci. Technol., 114, 974-982.

Pan, Y., Zhang, X., Wang, H., Liang, Y., Zhu, J., Li, H., Zhang, Z., Wu, Q. (2007). Antioxidant potential of ethanolic extract of Polygonum cuspidatum and application in peanut oil. Food Chemistry, 105, 1518-1524.

Rovellini, P., Cortesi, N., Fedeli, E. (1997). Ossidazioni dei lipidi. Nota 1. Rivista Italiana delle Sostanze Grasse 74, 181189.

Shahidi, F. (2005). Bailey's Industrial Oil \& Fat Products (Sixth edition), Volume 1, Edible Oil \& Fat Products:Chemistry, Properties and Health Effects, Eiley-Interscience publication: 269-513.

Siegmund, B., Murkovic, M. (2004). Changes in chemical composition of pumpkin seeds during the roasting process for production of pumpkin seed oil (Part 2: volatile compounds). Food Chemistry, 84, 367-374.

Stela, J., Moslavac, T., Bošnjak, A., Aladić, K., Rajić, M., Bilić, M. (2014). Optimisation of walnut oil production.Croat. J. Food Sci. Technol., 6 (1), 27-35.

Suja, K.P., Abraham, J.T., Thamizh, S.N., Jayalekshmy, A., Arumughan, C. (2004). Antioxidant efficacy of sesame cake extract in vegetable oil protection. Food Chemistry, 84, 393-400.

Teh, S.S., Birch, J. (2013). Physicochemical and quality characteristics of cold-pressed hemp, flax and canola seed oils. J. Food Compos. Anal., 30, 26-31.

Vukša, V., Dimić, E., Dimić, V. (2003). Characteristics of cold pressed pumpkin seed oil, $9^{\text {th }}$ Symposium: Vitamine und Zusatzstoffe in der Ernahrung von Mensch und Tier, Proceedings, pp. 493-496, Jena/Thuringen, 2003.

Zubr, J. (1997). Oil-seed crop: Camelina sativa. Ind. Crop. Prod., 6, 113-119. 


\title{
The impact of pressing conditions of pumpkin seeds and adding of antioxidants on yield and oxidative stability of cold pressed oils
}

\begin{abstract}
Pumpkin seed oil belongs to the group of exclusive and very expensive edible oils, and its nutritive quality justify the high price. In this study the influence of parameters cold pressing pumpkin seeds on yield oil was investigated. The following parameters such as electromotor frequency, nozzle size, the addition of the sunflower shell and the microwave heating of pumpkin seed to the oil production were studied. The increase in the electromotor frequency and nozzle size had resulted in a reduction in the amount of produced oil. By applying standard methods, basic oil quality parameters were determined: peroxide number, free fatty acid, percentage of insoluble impurities and moisture content. Also, the addition of a mixture of natural antioxidants to the oxidative stability of cold-pressed pumpkin oil was studied. The following antioxidants were used: pomegranate extract, rosemary extract (type Oxy'Less Clear), sea buckthorn essential oil and basil essential oil in combination with green tea extract. The oxidative stability of the pumpkin oil was determined by the accelerated oxidation test - Schaal Oven test $\left(63^{\circ} \mathrm{C}\right)$, and the result of oil oxidation was expressed by peroxide number. The research results show that the nozzle size and the electromotor frequency significantly influence on yield of cold pressed pumpkin seed oil. The best antioxidant effect in cold pressed pumpkin oil has shown the addition of green tea extract with an sea buckthorn essential oil. Key words: pumpkin seed oil, screw press, oxidative stability, natural antioxidants
\end{abstract}

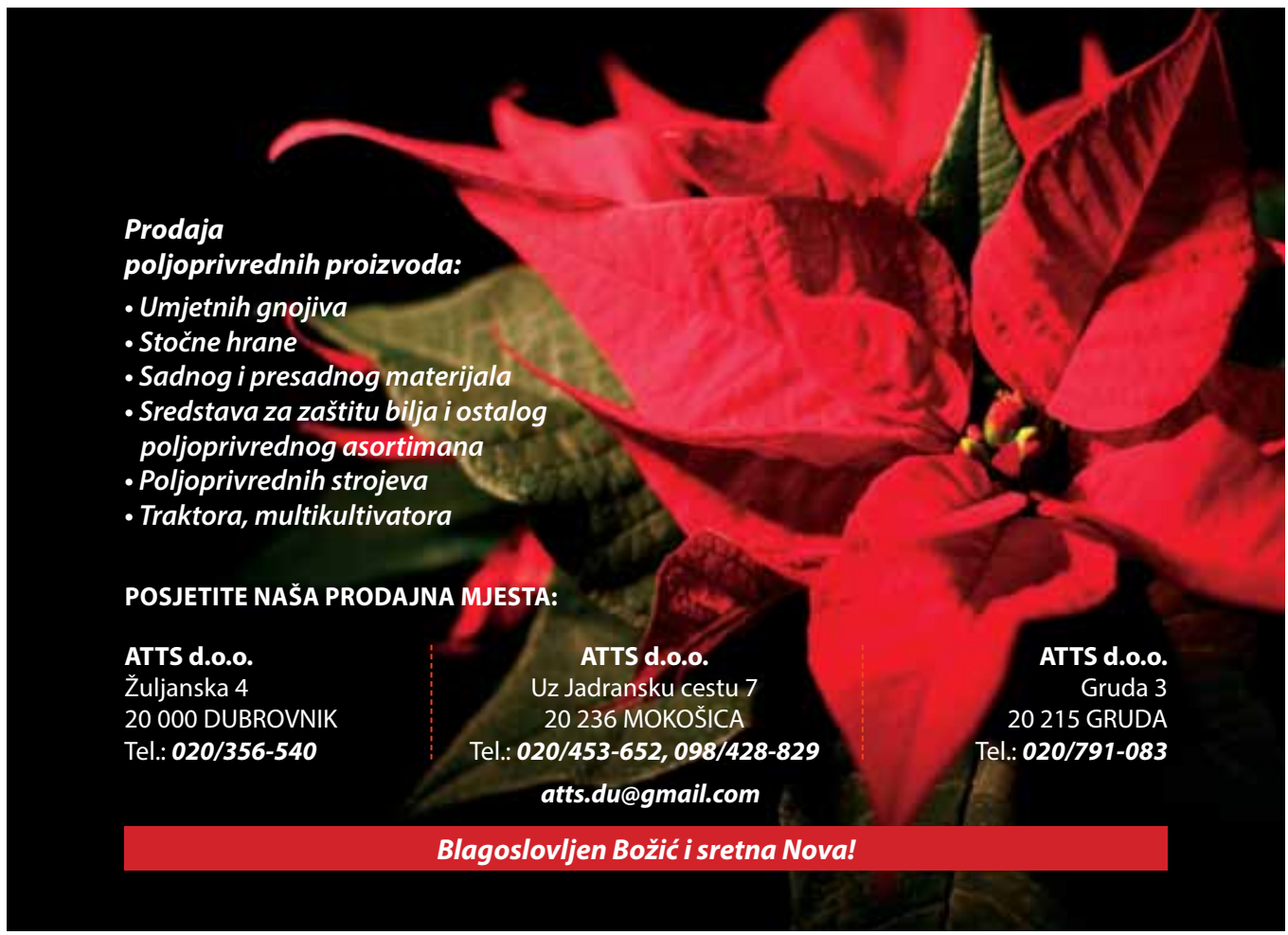

